Preface

\title{
Tissue Factor in Arterial and Venous Thrombosis: From Pathophysiology to Clinical Implications
}

\author{
Elena Tremoli, $\mathrm{PhD}^{1,2}$ \\ ${ }^{1}$ Department of Pharmacological and Biomolecular Sciences, \\ Università degli Studi di Milano, Milan, Italy \\ ${ }^{2}$ Centro Cardiologico Monzino IRCCS, Milan, Italy \\ Semin Thromb Hemost 2015;41:680-681.
}

The history of tissue factor (TF) goes back to the early 1960s with the discovery of brain thromboplastin and the documented evidence of its role in blood coagulation. ${ }^{1}$ Since 1987 several studies have documented the presence of this protein within human normal and pathological tissues, focusing on atherothrombotic diseases and cancer. ${ }^{2,3}$ Since the beginning of the new millennium, this scenario has been intensely studied.

TF is a 47-kDa glycoprotein that binds to activated factor VII (FVIIa), leading to activation of factor X (FX) and factor IX (FIX). TF-initiated coagulation is fundamental in inducing thrombosis in the arterial and venous compartments. Tissue distribution reveals that TF is expressed in perivascular tissue, resulting in rapid hemostasis upon vascular injury. In addition, TF is present within atherosclerotic plaques mostly associated with macrophages and smooth muscle cells. TF is not normally present within the circulating blood, but its expression can be induced in monocytes and neutrophils by a variety of agonists. Also, platelets have been recently shown to express TF upon activation. In addition, circulating microparticles (MPs) can provide consistent amounts of TF., 4

This issue of Seminars in Thrombosis E Hemostasis is focused on the role of TF in arterial and venous thrombosis, providing insights that span from pathophysiology to clinical implications. First, Gajsievwicz and Morrissey review the structure-function relationship of the interaction between TF and FVIIa, providing insights into their mechanistic activities in several biological processes. ${ }^{6}$ These concepts are extended to novel noncoagulant signaling mechanisms for the TF/VIIa complex, as cell migration and apoptosis, as pointed out by Åberg et al. ${ }^{7}$ Apart from cell- and vesselwall associated TF, the pathophysiological role of noncellassociated, and specifically of soluble, TF is addressed by Bogdanov and Versteeg. ${ }^{8}$ Cimmino et al then review the role of TF in coagulation and atherothrombosis, underlying the different mechanisms by which TF modulates this com-

Address for correspondence Elena Tremoli, PhD, Department of Pharmacological and Biomolecular Sciences, Università degli Studi di Milano and Centro Cardiologico Monzino IRCCS, Milan, Italy (e-mail: elena.tremoli@unimi.it).

plex network that comprises not only blood coagulation but also other processes, for example, intracellular signaling, proliferation, and angiogenesis. ${ }^{9}$ Of particular interest nowadays is the role of TF-bearing circulating microparticles; although some methodological aspects still need to be solved, their application as prognostic biomarkers in venous or arterial thrombosis is very promising, as highlighted by van Es et al. ${ }^{10}$ Neutrophils, which also express TF, may be physiological regulators of intravascular thrombosis, besides being the first line of defense of the immune system, as reviewed by Maugeri and Manfredi. ${ }^{11}$ In addition, a role of platelet TF can be proposed in patients with cardiovascular disease as highlighted by Camera et al. ${ }^{12}$ In particular, the fate of TF starting from the megakaryocyte up to the mature platelet is described. The articles by Versteeg and Falanga et al focus on the role of TF on cancer progression and on its relevance as a biomarker to assess the thrombotic risk in patients with cancer. ${ }^{13,14}$ Finally, Chiu et al review the role of protein disulphide isomerase (PDI) in thrombosis and discuss the proteins, including TF, characterized as PDI substrate. ${ }^{15}$

Moving from TF, in the last part of the issue, three contributions focus on the use of new oral anticoagulants as well as new hemostatic agents. No gender-related differences in safety and efficacy of direct oral anticoagulants (DOACs) are reported by Dentali et al in patients with atrial fibrillation (AF) or acute venous thromboembolism (VTE), with only a trend toward an increase in risk of bleeding in males as compared with females in the extended treatment of VTE. ${ }^{16}$ Increased bleeding is a major issue in the treatment with oral anticoagulants. In particular, Franchini et al review the management of bleeding associated with the use of DOACs, providing physicians with an algorithm for managing DOAC-associated bleeding. ${ }^{17}$ Finally, Franchini et al summarize new technologies and the current development status of the novel products for hemostasis, focusing in particular on

Copyright $\odot 2015$ by Thieme Medical Publishers, Inc., 333 Seventh Avenue, New York, NY 10001, USA.

Tel: +1(212) 584-4662.
DOI http://dx.doi.org/ 10.1055/s-0035-1564702. ISSN 0094-6176.
Arterial and Venous Thrombosis: From Pathophysiology to Clinical Implications; Guest Editors: Vincenzo Toschi, MD, and Massimo Franchini, MD. 
those with half-life extension for the treatment of hemophilia. $^{18}$

All the authors of this issue are thanked for their comprehensive contributions showing unique insights into TF and other aspects of thrombosis and hemostasis, and it is hoped that the readership finds interest in this issue of Seminars in Thrombosis E' Hemostasis.

\section{References}

1 Nemerson Y, Spaet TH. The activation of factor $\mathrm{X}$ by extracts of rabbit brain. Blood 1964;23(5):657-668

2 Ruf W. Tissue factor and cancer. Thromb Res 2012;130(Suppl 1): S84-S87

3 Owens AP III, Mackman N. Role of tissue factor in atherothrombosis. Curr Atheroscler Rep 2012;14(5):394-401

4 Camera M, Brambilla M, Facchinetti L, et al. Tissue factor and atherosclerosis: not only vessel wall-derived TF, but also plateletassociated TF. Thromb Res 2012;129(3):279-284

5 Kleinjan A, Böing AN, Sturk A, Nieuwland R. Microparticles in vascular disorders: how tissue factor-exposing vesicles contribute to pathology and physiology. Thromb Res 2012;130(Suppl 1): S71-S73

6 Gajsievwicz JM, Morrissey JM. Structure-function relationship of the interaction between tissue factor and factor VIIa. Semin Thromb Hemost 2015;41(7):682-690

7 Åberg M, Eriksson O, Siegbahn A. Tissue factor non-coagulant signaling: mechanisms and implications for cell migration and apoptosis. Semin Thromb Hemost 2015;41(7):691-699
8 Bogdanov VY, Versteeg HH. "Soluble Tissue Factor" in the 21th century: definitions, biochemistry, and pathophysiological role in thrombus formation. Semin Thromb Hemost 2015;41(7):700-707

9 Cimmino G, Ciccarelli G, Golino P. Role of tissue factor in the coagulation network. Semin Thromb Hemost 2015;41(7): 708-717

10 van Es N, Bleker S, Sturk A, Nieuwland R. Clinical significance of tissue factor-exposing microparticles in arterial and venous thrombosis. Semin Thromb Hemost 2015;41(7):718-727

11 Maugeri N, Manfredi AA. Tissue factor expressed by neutrophils: another piece in the vascular inflammation puzzle. Semin Thromb Hemost 2015;41(7):728-736

12 Camera M, Toschi V, Brambilla M, et al. The role of tissue factor in atherothrombosis and coronary artery disease: insights into platelet tissue factor. Semin Thromb Hemost 2015;41(7):737-746

13 Versteeg HH. Tissue factor: old and new links with cancer biology. Semin Thromb Hemost 2015;41(7):747-755

14 Falanga A, Schieppati F, Russo D. Cancer tissue procoagulant mechanisms and the hypercoagulable state of patients with cancer. Semin Thromb Hemost 2015;41(7):756-764

15 Chiu J, Passam F, Butera D, Hogg PJ. Protein disulfide isomerase in thrombosis. Semin Thromb Hemost 2015;41(7):765-773

16 Dentali F, Sironi AP, Gianni M, et al. Gender difference in efficacy and safety of direct oral anticoagulants in patients with nonvalvular atrial fibrillation or venous thromboembolism. A systematic review and a meta-analysis of the literature. Semin Thromb Hemost 2015;41(7):774-787

17 Franchini M, Bonfanti C, Mannucci PM. Management of bleeding associated with new oral anticoagulants. Semin Thromb Hemost 2015;41(7):788-801

18 Franchini M, Favaloro EJ, Lippi G. Newer hemostatic agents. Semin Thromb Hemost 2015;41(7):802-808 